\title{
Transition between vegetative phases in maize: genetic effects and variances and associated markers
}

\author{
B. ORdÁS, L. SERRANO, A. ORdÁS, A. BUTRÓN ANd P. REVILLA* \\ Misión Biológica de Galicia (CSIC), Apartado 28, E-36080 Pontevedra, Spain \\ (Revised MS received 17 January 2009; First published online 3 June 2009)
}

\begin{abstract}
SUMMARY
Transition from juvenile to adult vegetative phase in maize is associated with pest and disease resistance. However, reports are not consistent on the significance and relative importance of additive or dominance genetic effects and variances. The purpose of the present research was to elucidate the genetic effects and variances and to identify molecular markers associated with phase transition. Three cycles of divergent selection were carried out in a maize synthetic accelerating and delaying phase transition. Three and four inbred lines were released from the third cycles of late phase transition (LPT) and early phase transition (EPT), respectively. Generation mean analyses were performed from two LPT $\times$ EPT crosses in order to calculate genetic effects and variances. Markers associated with vegetative phase transition were identified by contrasting simple sequence repeat (SSR) alleles between LPT and EPT inbreds and selection cycles, and by testing whether drift could explain the allelic changes observed in the respective third cycles of selection. Juvenile traits are mainly regulated by additive genetic effects and variances, whereas adult traits have a complex regulation involving dominance and epistatic effects. Based on error variances, EPT improves phenotypic stability. The SSRs phi028, phi112 and umc1725 were associated with selection for phase transition, suggesting that these genome regions are involved in the regulation of vegetative phase transition of maize, although none of the genes previously associated with phase transition has been located in those regions.
\end{abstract}

\section{INTRODUCTION}

Maize vegetative development is divided into juvenile and adult phases, based on differences in leaf and stem morphology, anatomy and physiology, such as the presence of epicuticular wax in juvenile leaves (Poethig 1990). Earlier vegetative phase transition is associated with resistance to maize diseases and pests (Abedon \& Tracy 1996; Williams et al. 1998; Revilla et al. $2005 a, b$; Chandler \& Tracy $2007 a$; Basso et al. 2008; Riedeman et al. 2008).

The genetics of phase transition was initially studied in maize with mutants (Poethig 1990). Abedon et al. (1996) found that general combining ability was larger than specific combining ability for phasetransition-related traits; Abedon \& Tracy (1998) observed that these traits were unaffected by inbreeding depression and concluded that the genetic effects were

* To whom all correspondence should be addressed. Email: previlla@mbg.cesga.es mainly additive. In wild-type maize, Revilla et al. (2002) obtained a significant and clear response to divergent selection for early phase transition (EPT) and late phase transition (LPT), suggesting that additive effects were important and few genes were involved. Revilla et al. (2004) found that additive genetic variances were more important than dominance variances and the heritability of phasetransition-related traits was high. Chandler \& Tracy (2007b) found one simple sequence repeat (SSR) marker, bnlg127, significantly associated with vegetative phase change traits in a maize population, which mapped to the long arm of chromosome 9 near the gene Glossy15.

The inconsistencies among the published results could be due to the weakness of the genetic models used, the inadequacy of experimental designs, or the use of diverse materials, which were not purposely obtained for genetic studies. In a recent review of temperate crops, McMaster (2005) concluded that further studies are needed in order to understand the 
mechanisms controlling the phyllochron and phenology. In maize, a conclusive study of the genetics of phase transition is still lacking. In the present work, three cycles of divergent selection were conducted, inbred lines from the respective third cycles of selection were obtained and two generation mean analyses were designed, along with a molecular marker study for investigating the genetic effects and variances, and the genomic regions potentially associated with vegetative phase transition.

\section{MATERIALS AND METHODS}

\section{Field trials}

Inbred lines were released from the third cycles of a divergent selection programme for EPT and LPT in the maize synthetic EPS5 (Revilla et al. 2002). Inbred selection followed an ear-to-row selection programme by self-pollinating the plants, over 6 years, with fewer (EPT) or more (LPT) leaves with epicuticular wax from the respective third cycles of selection.

In order to analyse genetic effects, two pairs of inbreds with early (EPT1 and EPT2) and late (LPT1 and LPT2) phase transition were crossed. Crosses were self-pollinated and backcrossed, obtaining six generations per cross: EPTi, LPTi, EPTi $\times$ LPTi, $\left(\mathrm{EPTi} \times \mathrm{LPTi} \mathrm{F}_{2}, \quad(\mathrm{EPTi} \times \mathrm{LPTi}) \mathrm{EPTi}\right.$ and $(\mathrm{EPTi} \times$ LPTi)LPTi. The 12 entries were evaluated in 2007 at Pontevedra $\left(42^{\circ} 24^{\prime} \mathrm{N}, 8^{\prime} 38^{\prime} \mathrm{W}, 20 \mathrm{~m}\right.$ asl $)$ and Pontecaldelas $\left(42^{\circ} 23^{\prime} \mathrm{N}, 8^{\circ} 32^{\prime} \mathrm{W}, 300 \mathrm{~m}\right.$ asl $)$. Both locations have a humid climate with an annual rainfall of $1600 \mathrm{~mm}$ and are located in the northwest of Spain.

Trials followed a factorial design with three replications. Rows had 13 hills, each hill with two kernels that were later reduced to one plant. The distance between rows was $0.8 \mathrm{~m}$ and between hills $0.2 \mathrm{~m}$, giving a final plant density of 60000 plants/ha. Plots consisted of three rows for inbreds and hybrids, and five rows each for $F_{2}$ and backcross generations.

Traits related to the juvenile phase were last node with adventitious roots and number of leaves with epicuticular wax; traits related to the adult phase were first node with ear shoot, number of nodes with ear shoots and node of the uppermost ear, and other vegetative traits were plant and ear height and days to male and female flowering. Individual and combined analyses of variance across locations were calculated for each trait using SAS Proc MIXED (2000). Generations were considered fixed factors. For the mean generation analyses, each cross was considered a separate experiment. Since the number of plants evaluated for each entry was variable, the number of degrees of freedom (D.F.) used for the F-tests was obtained by the method of Satterthwaite (SAS 2000). The adjustment of the generation means to a genetic model was tested with a $\chi^{2}$ test. The test was applied to the simplest model and, if the $\chi^{2}$ revealed lack of fit, the next model was tried. The models considered were an additive model, an additive-dominant model, an additive-dominant model with epistasis, an additivedominant model with environmental effects and interactions and, finally, an additive-dominant model with both epistasis and environmental effects and interactions. If the data did not fit any of the first three models, the fourth one was assumed. After choosing the appropriate model, the genetic parameters estimated were $\mathrm{m}=$ mid-homozygote value, $\mathrm{a}=$ additive effects, $d=$ dominance effects and the non-allelic interactions: $a \mathrm{a}=$ additive $\times$ additive epistatic effects, $\mathrm{ad}=$ additive $\times$ dominance effects and $\mathrm{dd}=$ dominance $\times$ dominance epistatic effects, along with the corresponding interactions with environment (e) (Mather \& Jinks 1982).

The variances were calculated according to four different models, after choosing the model that fitted the data. The adjustment of the variances to a model was tested with a $\chi^{2}$ test. The test was applied to the simplest model and, if the $\chi^{2}$ revealed lack of fit, the next model was tried. The models considered were Model 1: the error variances of the parents and the hybrid were not significantly different, Model 2: the three error variances were different, Model 3: the error variances of the parents were not different but the error variance of the hybrid was different, Model 4: the error variances of the parent with late transition and of the hybrid were not different, but they differed from that of the parent with early transition, Model 5: the error variances of the parent with early transition and of the hybrid were not different, but they differed from that of the parent with late transition. For each model, there were three different submodels, 1: only the environmental variances were significant, 2: the environmental and the additive variances were significant, and 3: the environmental, the additive and the dominance variances were significant. After choosing a model, up to six variances were estimated: the three error variances of the LPT and EPT parents and the hybrid, and the additive, dominance and additive $\times$ dominance epistatic variances, along with the appropriate standard errors.

\section{Molecular markers}

Extractions of DNA were made from 96 plants from each population, EPS5 (the original synthetic), EPS5(EPT)C3 (the third cycle of selection for EPT) and EPS5(LPT)C3 (the third cycle of LPT), as well as from 10 plants for each of the seven inbred lines, following Liu \& Whittier (1994). SSR amplifications were performed as described by Butrón et al. (2003). SSR products were separated by electrophoresis using $1 \times$ TBE on a $60 \mathrm{mg} / \mathrm{g}$ non-denaturing gel of acrylamide $(c .250 \mathrm{~V}$ for $3 \mathrm{~h}$ ). Thirty-three SSR loci were chosen from among those provided in the Maize Genetics and Genomics Database (available online 
Table 1. Microsatellites (SSR) and chromosome location (bin) used to identify genome regions associated with vegetative phase transition in seven inbred lines derived from a divergent selection programme to delay and advance phase transition in the maize synthetic EPS5

\begin{tabular}{lllr}
\hline \hline SSR & \multicolumn{1}{c}{ Bin } & \multicolumn{1}{c}{ SSR } & Bin \\
\hline umc1222 & $1 \cdot 01-1 \cdot 02$ & umc1857 & $6 \cdot 04$ \\
phi109275 & $1 \cdot 03$ & umc2059 & $6 \cdot 08$ \\
umc1147 & $1 \cdot 07$ & phi112 & $7 \cdot 01$ \\
umc1725 & $1 \cdot 11$ & umc1154 & $7 \cdot 05$ \\
umc1165 & $2 \cdot 01$ & umc1984 & $8 \cdot 03$ \\
phi083 & $2 \cdot 04$ & bnlg240 & $8 \cdot 06$ \\
phi127 & $2 \cdot 08$ & umc1384 & $8 \cdot 08$ \\
umc1458 & $3 \cdot 02$ & phi028 & $9 \cdot 01$ \\
umc1174 & $3 \cdot 05$ & umc1492 & $9 \cdot 04$ \\
bnlg1318 & $4 \cdot 01$ & umc1505 & $9 \cdot 08$ \\
phi021 & $4 \cdot 03$ & umc1137 & $9 \cdot 08$ \\
phi092 & $4 \cdot 08$ & umc1318 & $10 \cdot 01$ \\
phi076 & $4 \cdot 11$ & umc2053 & $10 \cdot 01$ \\
umc1097 & $5 \cdot 00$ & phi301654 & $10 \cdot 04$ \\
phi113 & $5 \cdot 03-5 \cdot 04$ & umc1453 & $10 \cdot 04$ \\
bnlg1306 & $5 \cdot 07$ & umc1556 & $10 \cdot 07$ \\
bnlg161 & $6 \cdot 00$ & & \\
\hline \hline
\end{tabular}

at http://www.maizegdb.org (verified 5 May 2009)). These markers, distributed throughout the genome, were used to determine allelic frequencies in EPS5 and allele differences between the three and the four inbreds with LPT and EPT (Table 1). Fragments for each SSR locus were ordered and numbered according to increasing size. SAS software (SAS 2000) was used to perform the test of Schaffer (Schaffer et al. 1977), which checks whether the changes in allelic frequency between the original population and the cycles of selection could be explained solely by random drift. Departures from the model based on random drift were checked using a $\chi^{2}$ with one D.F. for comparisons between each third cycle of selection and the original population. The sum of squares for departures from the model based on random genetic drift involves a linear component the significance of which reveals whether allelic frequency changes are due to directional selection.

\section{RESULTS}

\section{Field trials}

Differences between generations were significant for most traits except number of nodes with ear shoots for both crosses and plant and ear height for the first cross (Table 2). The mean number of leaves with epicuticular wax of the six basic generations was clearly distributed from the late-transition parent (with the largest number of leaves with epicuticular wax) to the early-transition parent (with the lowest value), being intermediate for the other generations, depending on the proportion of each parent. Number of nodes with adventitious roots, node with the first ear shoot and node with the uppermost ear followed similar distributions to that of juvenile wax, although differences among generations were not so apparent (Table 2).

Plant and ear height did not differ significantly among the generations of the first cross and the means of the generations for the second cross were not related to the phase-transition traits. Similarly, the means for male and female flowering were not related to phase transition.

For both crosses, the additive genetic effects were highly significant for all phase-transition traits significantly differing among generations (Table 3). Furthermore, for all traits the estimate values of the additive effect were similar for both crosses: about 3 for last node with adventitious roots and number of leaves with epicuticular wax and 1.5 for first node with ear shoots and for the number of the nodes of the uppermost ear. For three of the phase-transition traits the dominance effects were consistent in both crosses, either significant but smaller than additive effects or not significant, while for the last node with adventitious roots the dominance effect was important in one cross, but not in the other. For number of leaves with epicuticular wax the epistatic effects were not important in either cross, whereas for the other phase-transition traits some epistatic effects were detected in one of the crosses. For EPT $1 \times$ LPT1, interaction of genetic effects with environments was detected for number of leaves with epicuticular wax and for number of nodes of the uppermost ear, but for EPT $2 \times$ LPT2, interaction of genetic effects with environments were not detected for any of the phasetransition traits.

Additive variance was significant for all the phasetransition traits in at least one of the crosses, while the dominance and the epistatic variance were only significant for one trait and only for one of the crosses (Table 4). The components of genetic variance were less consistent for different genotypes than the genetic effects.

All the error variance terms were significant and most of them were heterogeneous between both inbreds and between inbreds and hybrids (Table 4). Since hybrids are more stable than inbreds, a lower error variance would be expected for hybrids than for inbreds; however, the inbred with EPT had the lowest error variance more often than the hybrid, and the inbred with LPT had generally the largest error variance.

\section{Molecular markers}

The original screening showed clearly distinguishable variability within the maize synthetic EPS5 and 
Table 2. Means ( \pm S.E.) from generation mean analyses derived from LPT1 $\times E P T 1$ and $L P T 2 \times E P T 2$

\begin{tabular}{|c|c|c|c|c|c|c|c|c|c|}
\hline Generation & $\begin{array}{l}\text { Roots* } \\
\text { No. nodes }\end{array}$ & $\begin{array}{c}\text { Wax } \\
\text { No. leaves }\end{array}$ & $\begin{array}{c}\text { Shoot } \\
\text { No. nodes }\end{array}$ & $\begin{array}{l}N \text { shoots } \\
\text { No. nodes }\end{array}$ & $\begin{array}{l}\text { Up ear } \\
\text { No. nodes }\end{array}$ & $\begin{array}{l}\text { Plant } h \\
\quad(\mathrm{~m})\end{array}$ & $\begin{array}{l}\text { Ear } h \\
(\mathrm{~mm})\end{array}$ & $\begin{array}{l}\text { Male } f \\
\text { (days) }\end{array}$ & $\begin{array}{c}\text { Female } f \\
\text { (days) }\end{array}$ \\
\hline \multicolumn{10}{|l|}{ LPT $1 \times$ EPT 1} \\
\hline LPT1 & $8 \pm 0 \cdot 5$ & $12 \pm 0 \cdot 7$ & $12 \pm 1 \cdot 0$ & $2 \pm 0 \cdot 4$ & $12 \pm 1 \cdot 3$ & $1.48 \pm 0.32$ & $500 \pm 194$ & $86 \pm 1 \cdot 2$ & $88 \pm 1 \cdot 3$ \\
\hline EPT1 & $6 \pm 0 \cdot 5$ & $5 \pm 0 \cdot 7$ & $9 \pm 1 \cdot 0$ & $2 \pm 0 \cdot 4$ & $9 \pm 1 \cdot 3$ & $1 \cdot 21 \pm 0.32$ & $220 \pm 318$ & $82 \pm 1 \cdot 2$ & $84 \pm 1 \cdot 3$ \\
\hline F1 & $7 \pm 0 \cdot 5$ & $8 \pm 0 \cdot 7$ & $10 \pm 1 \cdot 0$ & $2 \pm 0 \cdot 4$ & $11 \pm 1 \cdot 3$ & $1.68 \pm 0.32$ & $440 \pm 318$ & $79 \pm 1 \cdot 2$ & $81 \pm 1 \cdot 3$ \\
\hline F2 & $7 \pm 0 \cdot 5$ & $8 \pm 0.7$ & $10 \pm 1 \cdot 0$ & $2 \pm 0 \cdot 4$ & $11 \pm 1 \cdot 3$ & $1 \cdot 50 \pm 0.32$ & $370 \pm 318$ & $80 \pm 1 \cdot 2$ & $82 \pm 1 \cdot 3$ \\
\hline $\mathrm{BC} 1$ & $8 \pm 0.5$ & $10 \pm 0 \cdot 7$ & $11 \pm 1 \cdot 0$ & $2 \pm 0 \cdot 4$ & $12 \pm 1 \cdot 3$ & $1.58 \pm 0.32$ & $480 \pm 318$ & $80 \pm 1 \cdot 2$ & $83 \pm 1 \cdot 3$ \\
\hline $\mathrm{BC} 2$ & $7 \pm 0.5$ & $6 \pm 0 \cdot 7$ & $10 \pm 1 \cdot 0$ & $2 \pm 0 \cdot 4$ & $10 \pm 1 \cdot 3$ & $1.55 \pm 0.32$ & $370 \pm 318$ & $79 \pm 1 \cdot 2$ & $80 \pm 1 \cdot 3$ \\
\hline Mean \pm S.E. & $7 \pm 0.5$ & $8 \pm 0.7$ & $10 \pm 1 \cdot 0$ & $2 \pm 0 \cdot 4$ & $11 \pm 1 \cdot 3$ & $1.50 \pm 0.32$ & $400 \pm 318$ & $81 \pm 1 \cdot 2$ & $83 \pm 1 \cdot 3$ \\
\hline \multicolumn{10}{|l|}{ LPT $2 \times$ EPT 2} \\
\hline LPT2 & $7 \pm 0 \cdot 5$ & $11 \pm 0 \cdot 8$ & $12 \pm 0 \cdot 6$ & $2 \pm 0 \cdot 5$ & $12 \pm 0 \cdot 5$ & $1 \cdot 63 \pm 0 \cdot 17$ & $550 \pm 55$ & $87 \pm 2 \cdot 1$ & $88 \pm 1 \cdot 2$ \\
\hline EPT2 & $6 \pm 0.5$ & $5 \pm 0 \cdot 8$ & $9 \pm 0.6$ & $1 \pm 0.5$ & $10 \pm 0.5$ & $1 \cdot 14 \pm 0 \cdot 17$ & $270 \pm 55$ & $83 \pm 2 \cdot 1$ & $86 \pm 1 \cdot 2$ \\
\hline $\mathrm{F} 1$ & $6 \pm 0.5$ & $7 \pm 0.8$ & $11 \pm 0 \cdot 6$ & $2 \pm 0.5$ & $11 \pm 0.5$ & $1.75 \pm 0.17$ & $650 \pm 55$ & $78 \pm 2 \cdot 1$ & $78 \pm 1 \cdot 2$ \\
\hline $\mathrm{F} 2$ & $6 \pm 0.5$ & $8 \pm 0.8$ & $10 \pm 0 \cdot 6$ & $2 \pm 0.5$ & $11 \pm 0.5$ & $1.55 \pm 0.17$ & $500 \pm 55$ & $78 \pm 2 \cdot 1$ & $79 \pm 1 \cdot 2$ \\
\hline $\mathrm{BC} 1$ & $6 \pm 0.5$ & $9 \pm 0.8$ & $10 \pm 0 \cdot 6$ & $2 \pm 0.5$ & $11 \pm 0.5$ & $1.68 \pm 0.17$ & $550 \pm 55$ & $77 \pm 2 \cdot 1$ & $79 \pm 1.2$ \\
\hline $\mathrm{BC} 2$ & $6 \pm 0 \cdot 5$ & $6 \pm 0 \cdot 8$ & $9 \pm 0 \cdot 6$ & $2 \pm 0.5$ & $10 \pm 0.5$ & $1 \cdot 42 \pm 0.17$ & $440 \pm 55$ & $77 \pm 2 \cdot 1$ & $78 \pm 1 \cdot 2$ \\
\hline Mean \pm S.E. & $6 \pm 0.5$ & $8 \pm 0.8$ & $10 \pm 0 \cdot 6$ & $2 \pm 0.5$ & $11 \pm 0.5$ & $1.52 \pm 0.17$ & $490 \pm 55$ & $80 \pm 2 \cdot 1$ & $81 \pm 1 \cdot 2$ \\
\hline
\end{tabular}

* Roots, last node with adventitious roots; wax, number of leaves with epicuticular wax; shoot, first node with ear shoots; $N$ shoots, number of nodes with ear shoots; up ear, number of nodes of the uppermost ear; plant $h$, plant height; ear $h$, ear height; male $f$, days to male flowering; female $f$, days to female flowering.

among its 16 inbred parents for SSRs. Among the 33 SSRs used to compare the three and the four inbred lines with LPT and EPT, respectively, four SSRs differed for allele composition between LPT and EPT groups: umc1725, phi112, phi028 and umc1453.

These four SSRs were used for screening the respective third cycles of early EPS5(EPT)C3 and late EPS5(LPT)C3 phase transition. The SSR alleles detected in EPS5 were maintained through selection and none of the alleles disappeared or was fixed (Table 5). Some of the modifications in allele frequencies were consistent, i.e. decreased with EPT and increased with LPT or vice versa; in particular, all the alleles of phil12 varied consistently, whereas none of the alleles of umc1725 did so. Some of the alleles increased or decreased simultaneously in both the directions of selection, particularly the allele $u m c 1725-b$.

The significance of allele changes was checked following Schaffer et al. (1977). None of the changes of allele frequencies detected for umc1453 was significant, whereas for umc1725 two of the three alleles suffered significant modifications of frequency (Table 5). Five of the six significant changes of allele frequencies were associated with selection for EPS, whereas only one with LPT.

Frequencies varied consistently with selection for all the alleles of phi112, although only phi112-b varied significantly for EPS5(EPT)C3. For phi028, the frequency of the allele phi028-c significantly $(P=0 \cdot 01)$ increased with selection for EPS and varied accordingly for LPT. Moreover, the allele phi028- $a$ could be related to selection for EPT $(P=0 \cdot 10)$, although it did not vary consistently for LPT.

\section{DISCUSSION}

\section{Field trials}

Most phase-transition traits differed between genotypes and the comparisons of means agreed with expectations based on the values of the parents. However, differences among genotypes for the agronomic traits did not follow a similar distribution. Therefore, no clear relationship was found between phasetransition and agronomic traits. Chandler \& Tracy (2007a) also did not find a relationship between phase-transition and some agronomic traits, such as plant and ear height. However, Revilla et al. (2004) reported a significant additive correlation between phase transition and plant and ear height and flowering dates in the original synthetic before selection was carried out. Correlations could have changed due to the selection process. Abedon et al. (1996) found some significant correlations between last leaf with juvenile wax and other phase-transition traits, but phase transition was not significantly correlated with vegetative or agronomic traits. Abedon et al. (1996) reported high positive correlation between ear leaf number and days to male and female flowering and plant and ear height, which were not apparent in the present work. Tojo Soler et al. (2005) explained that the number of leaves depends on the phyllochron or thermal interval between the appearances of successive leaves, which in turn affects the duration of the vegetative development; therefore, environmental differences between trials could explain most discrepancies between experiments. Abedon et al. (1996) calculated simple correlations in six distinct 
Table 3. Estimates of mid homozygote $(m)$, additive (a), dominance (d), epistasis (aa, ad and dd), environmental (e) and parameter $\times$ environment interaction pooled effects \pm S.E. and $\chi^{2}$ test from generation mean analysis derived from $E P T 1 \times L P T 1$ and $E P T 2 \times L P T 2$

\begin{tabular}{|c|c|c|c|c|c|}
\hline Parameter & $\begin{array}{l}\text { Roots* } \\
\text { No. nodes }\end{array}$ & $\begin{array}{c}\text { Wax } \\
\text { No. leaves }\end{array}$ & $\begin{array}{c}\text { Shoot } \\
\text { No. nodes }\end{array}$ & $\begin{array}{l}N \text { shoots } \\
\text { No. nodes }\end{array}$ & $\begin{array}{l}\text { Upper ear } \\
\text { No. nodes }\end{array}$ \\
\hline \multicolumn{6}{|c|}{ EPT $1 \times$ LPT 1} \\
\hline $\mathrm{m}$ & $6 \pm 1 \cdot 0$ & $8 \pm 0 \cdot 2$ & $9 \pm 0 \cdot 7$ & $2 \pm 0 \cdot 1$ & $11 \pm 0 \cdot 1$ \\
\hline $\mathrm{a}$ & $3 \pm 0 \cdot 2$ & $4 \pm 0 \cdot 2$ & $1 \pm 0 \cdot 1$ & $0 \cdot 1 \pm 0.07$ & $2 \pm 0 \cdot 1$ \\
\hline d & $6 \pm 2 \cdot 4$ & $-1 \pm 0 \cdot 3$ & $2 \pm 1 \cdot 6$ & $-0 \cdot 1 \pm 0 \cdot 14$ & $-0 \cdot 1 \pm 0.23$ \\
\hline aa & $3 \pm 1 \cdot 0$ & & $1 \pm 0 \cdot 6$ & & \\
\hline $\mathrm{ad}$ & $2 \pm 0.7$ & & $1 \pm 0 \cdot 5$ & & \\
\hline $\mathrm{dd}$ & $-4 \pm 1 \cdot 5$ & & $-1 \pm 1 \cdot 0$ & & \\
\hline $\mathrm{e}$ & $0 \cdot 3 \pm 0 \cdot 10$ & $0 \cdot 5 \pm 0 \cdot 18$ & $1 \pm 0.7$ & $-0 \cdot 1 \pm 0.08$ & $0 \cdot 1 \pm 0 \cdot 13$ \\
\hline ae & & $1 \pm 0 \cdot 2$ & $-0 \cdot 1 \pm 0 \cdot 13$ & $-0.1 \pm 0.07$ & $0 \cdot 1 \pm 0 \cdot 12$ \\
\hline de & & $-0.2 \pm 0.33$ & $-0.3 \pm 1.58$ & $0.5 \pm 0.14$ & $1 \pm 0.2$ \\
\hline aae & & & $-1 \pm 0 \cdot 6$ & & \\
\hline ade & & & $1 \pm 0.5$ & & \\
\hline dde & & & $0 \cdot 1 \pm 1 \cdot 00$ & & \\
\hline$\chi^{2}$ (D.F.) & $3 \cdot 8(5)$ & $8 \cdot 7(6)$ & $\dagger$ & $4 \cdot 3(6)$ & $10 \cdot 4(6)$ \\
\hline \multicolumn{6}{|c|}{ EPT $2 \times$ LPT 2} \\
\hline $\bar{m}$ & $8 \pm 0 \cdot 1$ & $8 \pm 0 \cdot 2$ & $11 \pm 0 \cdot 6$ & $1 \pm 0 \cdot 41$ & $11 \pm 0 \cdot 7$ \\
\hline $\mathrm{a}$ & $3 \pm 0 \cdot 2$ & $3 \pm 0 \cdot 1$ & $2 \pm 0 \cdot 1$ & $-0 \cdot 4 \pm 0 \cdot 15$ & $1 \pm 0 \cdot 1$ \\
\hline d & & $-1 \pm 0 \cdot 2$ & $-3 \pm 1 \cdot 5$ & $2 \pm 1.03$ & $-1 \pm 1.7$ \\
\hline aa & & & $-1 \pm 0 \cdot 6$ & $1 \pm 0 \cdot 4$ & $-0.4 \pm 0.68$ \\
\hline $\mathrm{ad}$ & & & $-1 \pm 0 \cdot 4$ & $0.3 \pm 0.38$ & $-1 \pm 0.5$ \\
\hline $\mathrm{dd}$ & & & $3 \pm 0.9$ & $-1 \pm 0 \cdot 7$ & $2 \pm 1 \cdot 1$ \\
\hline $\mathrm{e}$ & $0 \cdot 1 \pm 0 \cdot 10$ & $0 \cdot 1 \pm 0 \cdot 10$ & $0 \cdot 3 \pm 0 \cdot 06$ & $-0 \cdot 1 \pm 0 \cdot 41$ & $0.4 \pm 0.07$ \\
\hline ae & & & & $0 \cdot 1 \pm 0 \cdot 15$ & \\
\hline $\mathrm{de}$ & & & & $0 \cdot 4 \pm 1 \cdot 03$ & \\
\hline aae & & & & $0 \cdot 1 \pm 0 \cdot 38$ & \\
\hline ade & & & & $-1 \pm 0 \cdot 4$ & \\
\hline dde & & & & $-0.1 \pm 0.65$ & \\
\hline$\chi^{2}$ (D.F.) & $14 \cdot 2(9)$ & $6 \cdot 4(9)$ & $6 \cdot 8(5)$ & + & $7 \cdot 2(5)$ \\
\hline
\end{tabular}

* Roots, last node with adventitious roots; wax, number of leaves with epicuticular wax; shoot, first node with ear shoots; $N$ shoots, number of nodes with ear shoots; up ear, number of nodes of the uppermost ear; plant $h$, plant height; ear $h$, ear height; male $f$, days to male flowering; female $f$, days to female flowering.

$\dagger$ The $\chi^{2}$ could not be calculated because these data did not fit any model; therefore, D.F. cannot be stated.

populations and the current report presents a correlated response to selection in a single synthetic. Therefore, the relationships, and hence the correlated responses to selection, strongly depend on the genetic material involved. Inbred lines were used in the present study, whereas varieties were used in the earlier experiments, and Abedon \& Tracy (1998) found that phase-transition traits are relatively unaffected by inbreeding and heterosis, while most agronomic traits are significantly affected.

The additive effects were the most important for phase-transition traits and the additive variance was consistently the main component of genetic variance for phase transition. However, some dominance and epistatic effects were also detected and those effects produced for some particular traits and for each cross a significant genetic variance. Accordingly, most maize traits are generally regulated by additive genetic effects, with minor contribution of dominance or epistatic effects; although yield and other traits significantly affected by heterosis show larger dominance effects (Alonso Ferro et al. 2008).

Revilla et al. (2004) calculated the genetic variances with the same maize synthetic used for the present study and found that only the additive variance was significant for last leaf with juvenile wax, whereas the dominance and the epistatic variances were not significant, and their magnitudes were lower than the additive variance. The results of Revilla et al. (2004) partially agree with the present results based on genetic effects, except that the dominance variances were not significant in the 2004 study and the dominance effects were significant in the present one, along with the dominance variance for the second cross. This disagreement could be explained by the large errors associated with calculations of dominance variances with the North Carolina Design I, and also by the non-significant effects of heterosis and inbreeding 
Table 4. Estimates of variance components corresponding to the error $(V e)$, additive $(V a)$, dominance $(V d)$ and epistatic (Vad) terms, for $(E P T 1 \times L P T 1) F_{2}$ and $(E P T 2 \times L P T 2) F_{2}$ following the models $1-5$ described in materials and methods

\begin{tabular}{|c|c|c|c|c|c|}
\hline Parameter & Roots* & Wax & Shoot & $N$ shoots & Up ear \\
\hline$(\mathrm{LPT} 1 \times \mathrm{EPT} 1) \mathrm{F}_{2}$ & Model 4 & Model 2 & Model 5 & Model 2 & Model 3 \\
\hline Ve (LPT1) & $0 \cdot 8 \pm 0 \cdot 10$ & $3.7 \pm 0.78$ & $1 \cdot 6 \pm 0.33$ & $2 \cdot 4 \pm 0 \cdot 47$ & $1 \cdot 4 \pm 0 \cdot 20$ \\
\hline Ve (EPT1) & $0.3 \pm 0.06$ & $0.6 \pm 0.11$ & $0.7 \pm 0.09$ & $0 \cdot 3 \pm 0.05$ & $=\mathrm{Ve}(\mathrm{LPT} 1)$ \\
\hline $\mathrm{Ve}\left(\mathrm{F}_{1}\right)$ & $=\mathrm{Ve}(\mathrm{LPT} 1)$ & $1.0 \pm 0.19$ & $=\mathrm{Ve}(\mathrm{EPT} 1)$ & $0 \cdot 2+0.03$ & $0 \cdot 6+0 \cdot 11$ \\
\hline $\mathrm{Va}$ & $0.6+0.25$ & $1.7 \pm 0.61$ & $0.4+0.35$ & $0 \cdot 1+0 \cdot 08$ & $1 \cdot 0+0 \cdot 43$ \\
\hline $\mathrm{Vd}$ & $-0 \cdot 4 \dagger$ & $-1 \cdot 0$ & $-0 \cdot 1 \dagger$ & $-0 \cdot 5 \dagger$ & $-0.5 \dagger$ \\
\hline Vad & & $0.4 \pm 0.23$ & $0 \cdot 3 \pm 0 \cdot 13$ & $0 \cdot 6 \pm 0 \cdot 12$ & \\
\hline$\chi^{2}$ (D.F.) & $2 \cdot 33(2)$ & + & $7 \cdot \overline{30}(1)$ & $\$$ & $0 \cdot 74(2)$ \\
\hline$(\mathrm{LPT} 2 \times \mathrm{EPT} 2) \mathrm{F}_{2}$ & Model 3 & Model 4 & Model 4 & Model 1 & Model 1 \\
\hline Ve (LPT2) & $0 \cdot 4 \pm 0 \cdot 06$ & $0 \cdot 8 \pm 0 \cdot 10$ & $0 \cdot 9 \pm 0 \cdot 11$ & $0 \cdot 3 \pm 0 \cdot 03$ & $0.7 \pm 0.08$ \\
\hline $\mathrm{Ve}(\mathrm{EPT} 2)$ & $=\mathrm{Ve}(\mathrm{LPT} 2)$ & $0.4 \pm 0.08$ & $0 \cdot 5 \pm 0 \cdot 11$ & $=\operatorname{Ve}($ LPT2 $)$ & $=\mathrm{Ve}(\mathrm{LPT} 2)$ \\
\hline $\mathrm{Ve}\left(\mathrm{F}_{1}\right)$ & $0.9 \pm 0.09$ & $=\mathrm{Ve}(\mathrm{LPT} 2)$ & $=\mathrm{Ve}(\mathrm{LPT} 2)$ & $=\mathrm{Ve}($ LPT2 $)$ & $=\mathrm{Ve}(\mathrm{LPT} 2)$ \\
\hline $\mathrm{Va}$ & & $0.2 \pm 0.72$ & $1 \cdot 3 \pm 0 \cdot 40$ & $-0.96 \dagger$ & $1.3 \pm 0.38$ \\
\hline $\mathrm{Vd}$ & & $1.5 \pm 0.53$ & $-0.6 \dagger$ & $2 \cdot 0 \pm 0 \cdot 24$ & $-0 \cdot 6+$ \\
\hline Vad & & $-1 \cdot 1$ & $0.1 \pm 0.08$ & & \\
\hline$\chi^{2}$ (D.F.) & $0.40(4)$ & $0.48(1)$ & $0.90(1)$ & $2 \cdot 24(3)$ & $3 \cdot 83(3)$ \\
\hline
\end{tabular}

* Roots, last node with adventitious roots; wax, number of leaves with epicuticular wax; shoot, first node with ear shoots; $N$ shoots, number of nodes with ear shoots; up ear, number of nodes of the uppermost ear; plant $h$, plant height; ear $h$, ear height; male $f$, days to male flowering; female $f$, days to female flowering.

$\uparrow$ The standard error was not calculated because the variance estimate is negative.

\$ The $\chi^{2}$ cannot be calculated because there are no D.F. left after calculating six parameters.

Table 5. Allele frequencies in the maize synthetic EPS5 and the third cycles of early [EPS5(EPT)C3] and late $[E P S 5(L P T) C 3]$ phase transition for the four SSR differing between the three and four inbred lines with LPT and $E P T$

\begin{tabular}{|c|c|c|c|c|c|c|c|}
\hline SSR & Allele & EPS5(LPT)C3 & $P^{*}$ & EPS5 & $P$ & EPS5(EPT)C3 & $P$ \\
\hline \multirow[t]{4}{*}{ phil12 } & $\mathrm{a}$ & $0 \cdot 27$ & . & 0.29 & . & $0 \cdot 31$ & 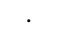 \\
\hline & b & $0 \cdot 64$ & & 0.57 & & 0.44 & $0 \cdot 10$ \\
\hline & $\mathrm{c}$ & 0.08 & & $0 \cdot 11$ & & $0 \cdot 17$ & \\
\hline & d & $0 \cdot 01$ & & 0.03 & & 0.09 & \\
\hline \multirow[t]{3}{*}{ phi028 } & $\mathrm{a}$ & $0 \cdot 20$ & & $0 \cdot 21$ & & 0.06 & $0 \cdot 10$ \\
\hline & b & $0 \cdot 25$ & & $0 \cdot 15$ & & $0 \cdot 10$ & \\
\hline & $\mathrm{c}$ & 0.55 & & 0.65 & & $0 \cdot 84$ & $0 \cdot 01$ \\
\hline \multirow[t]{2}{*}{ umc1453 } & $\mathrm{a}$ & $0 \cdot 74$ & & 0.73 & & 0.78 & \\
\hline & b & $0 \cdot 28$ & & $0 \cdot 27$ & & $0 \cdot 22$ & \\
\hline \multirow[t]{3}{*}{ umc1725 } & $\mathrm{a}$ & $0 \cdot 10$ & & 0.06 & & $0 \cdot 21$ & $0 \cdot 10$ \\
\hline & b & $0 \cdot 43$ & 0.05 & 0.62 & & 0.43 & $0 \cdot 01$ \\
\hline & $\mathrm{c}$ & 0.47 & & $0 \cdot 36$ & & $0 \cdot 36$ & \\
\hline
\end{tabular}

* Significantly different from the changes in allele frequencies expected solely by random drift (Schaffer et al. 1977). Blank cells indicate $P>0 \cdot 05$.

on phase-transition traits, compared to the usually high effect on agronomic traits. In addition, the intermediate frequencies produced in the mean generation analysis as a consequence of crossing two inbred lines derived from divergent selection tend to maximize the dominance effects. The present results are in agreement with the previous report by Abedon et al. (1996), who found significant general combining ability for leaves with juvenile wax and other phasetransition-related traits, while neither specific combining ability nor interactions with environment were significant. Similarly, Abedon \& Tracy (1998) suggested that additive effects were more important than dominance effects on the genetic variability of phase transition. Also, in other crops the duration of vegetative development has been found to be quite 
predictable across environments and unaffected by genotype $\times$ environment interactions (Hurley et al. 2008).

The present results suggest that the reduction of the juvenile phase increases stability. Interestingly, Revilla et al. (2000) detected a reduction on juvenility in cultivated maize compared with the wild relatives and in the most productive maize race, Corn Belt Dent, compared with its ancestors. Such reduction on juvenility has paralleled an increase in stability during maize breeding, which was a correlated response to the yield increase continuously experienced (Tollenaar \& Lee 2002). The importance of variability along the growing cycle for increasing yield stability has been emphasized also for other crops (Browne et al. 2006). Therefore, it might be worthwhile to pay attention to vegetative phase transition as a component of stability.

\section{Molecular markers}

Three of 33 markers exhibited changes in allele frequency associated with the selection programme. Not all of the significant molecular changes can be attributed to selection for phase transition because some of those changes could be due to selection for performance that unavoidably accompanies any selection programme rather than to phase transition.

Among the four SSRs differing between inbred lines, umc1725, phi112, phi028 and umc1453, the last one did not show significant differences on allele frequencies between EPS5 and EPS5(EPT)C3 or EPS5(LPT)C3. Averaged over the four SSRs, there were three alleles per locus in EPS5, some of them with low frequency, such as umc1725-a (0.06), or with large frequency, as umc1453-a (0.73); and none of them was lost or fixed through selection, meaning that the presumed effect of these genome regions on phase transition was not as important as the effect of other genes previously described (Poethig 1988).

The consistent modifications of allele frequencies are compatible with a linear association with selection for phase transition, at least when deviations from random drift are significant (Schaffer et al. 1977). However, some allele frequencies diverged significantly for EPS5(EPT)C3 and not significantly for EPS5(LPT)C3. The allele $u m c 1725-b$ decreased significantly in both directions of selection, whereas the allele umc1725- $a$ increased, though not significantly, for LPT. This SSR is located in a genomic region that should have some selective value since the frequencies of those alleles were affected by selection.

Differences among populations for leaves with juvenile wax were quite important, with a reduction of $15 \%$ for EPS5(EPT)C 3 and an increase of $42 \%$ for EPS5(LPT)C3, particularly for LPT. In contrast, at the molecular level, the magnitude and proportion of changes of allele frequencies were more important for the early than for the late selection. Therefore, selection to reduce the juvenile phase is more difficult but causes more genetic changes that tend to increase the number of leaves with epicuticular wax.

In conclusion, it appears that a longer juvenile phase involves a reduction in stability. This implies not only greater susceptibility to stresses, pests and diseases, but also a rise of the variance and experimental error, as reported by Revilla et al. (2005b). This rationale is consistent with the larger impact of pests on genotypes with shorter juvenile phase observed by Abedon \& Tracy $(1996,1998)$ and Revilla et al. (2005a), as well as with the reduction of juvenile vegetative features observed during the domestication of maize (Revilla et al. 2000) and along breeding history.

Some particular genes have significant effects on phase transition; standing out some loci showing major mutants that alter phase transition (Poethig 1988), along with other mutants with primary effects on a diverse phenotypic aspect but with epistatic effects on phase transition, as shrunken2 (Revilla et al. $2005 b$ ). Moreover, other loci, which wild-type alleles have minor effects, as the potential candidate gene associated with the marker reported by Chandler \& Tracy $(2007 b)$ or those reported here. In all those previous reports, the number of loci explaining variability for phase transitions was very limited, but the loci identified depended on the genotype. This was particularly evident for the isogenic sul/sh 2 couples of inbreds (Revilla et al. 2005 b). Therefore, phase transition usually depends on few genes with large additive effects, but the genes involved are not consistent across genotypes.

This research was supported by the Spanish National Plan for Research and Development (AGF2004-06776).

\section{REFERENCES}

Abedon, B. G. \& Tracy, W. F. (1996). Corngrass 1 of maize (Zea mays L.) delays development of adult plant resistance to common rust (Puccinia sorghi Schw.) and European corn borer (Ostrinia nubilalis Hubner). Journal of Heredity 87, 219-223.

Abedon, B. G. \& Tracy, W. F. (1998). Inbreeding and the timing of vegetative phase change in maize (Zea mays L.). Maydica 43, 143-146.
Abedon, B. G., Revilla, P. \& Tracy, W. F. (1996). Vegetative phase change in sweet corn populations: genetics and relationships with agronomic traits (vegetative phase change in open-pollinated sweet corn). Maydica 41, 77-82.

Alonso Ferro, R. C., Malvar, R. A., Revilla, P., Ordás, A., Castro, P. \& Moreno-González, J. (2008). Genetics of quality and agronomic traits in hard 
endosperm maize. The Journal of Agricultural Science, Cambridge 146, 551-560.

Basso, C. F., Hurkman, M. M., Riedeman, E. S. \& Tracy, W. F. (2008). Divergent selection for vegetative phase change in maize and indirect effects on response to Puccinia sorghi. Crop Science 48, 992-999.

Browne, R. A., White, E. M. \& Burke, J. I. (2006). Responses of developmental yield formation processes in oats to variety, nitrogen, seed rate and plant growth regulator and their relationship to quality. The Journal of Agricultural Science, Cambridge 144, 533-545.

Butrón, A., Tarrio, R., Revilla, P., Malvar, R. A. \& Ordás, A. (2003). Molecular evaluation of two methods for developing maize synthetic varieties. Molecular Breeding 12, 329-333.

Chandler, M. A. \& Tracy, W. F. (2007a). Vegetative phase change among sweet corn (Zea mays L.) hybrids varying for reaction to common rust (Puccinia sorghi Schw.). Plant Breeding 126, 569-573.

Chandler, M. A. \& Tracy, W. F. (2007b). Identification of genomic regions affecting vegetative phase change in a sweet corn (Zea mays L.) population. Maydica 52, 407414.

Hurley, G., Gilliland, T. J. \& O'Donovan, M. (2008). Relationship between reproductive initiation and ear emergence development in Lolium perenne L. The Journal of Agricultural Science, Cambridge 146, 655-665.

LiU, Y. G. \& WhitTier, R. F. (1994). Rapid preparation of megabase plant DNA from nuclei in agarose plug and microbeads. Nucleic Acids Research 22, 21682169.

Mather, K. \& Jinks, J. L. (1982). Biometrical Genetics. 3rd edn. New York: Chapman and Hall.

McMaster, G. S. (2005). Phytomers, phyllochrons, phenology and temperate cereal development. The Journal of Agricultural Science, Cambridge 143, 137-150.

Poethig, R. S. (1988). Heterochronic mutations affecting shoot development in maize. Genetics 119, 959-973.

Poethig, R. S. (1990). Phase change and the regulation of shoot morphogenesis in plants. Science 250, 923-930.

Revilla, P., Velasco, P., Malvar, R. A., Soengas, P. \& OrdÁs, A. (2000). Variability for phase transition among races of maize and related wild forms. Maydica $\mathbf{4 5}$, $35-44$.
Revilla, P., Malvar, R. A., Butrón, A., Tracy, W. F., Abedon, B. G. \& Ordás, A. (2002). Response to selection for the timing of vegetative phase transition in a maize population. Crop Science 42, 1471-1474.

Revilla, P., Malvar, R. A., Butrón, A., Tracy, W. F., Abedon, B. G. \& Ordás, A. (2004). Genetics of the timing of vegetative phase transition in a maize population. Plant Breeding 123, 585-586.

Revilla, P., Malvar, R. A., Velasco, P., Butrón, A., Tracy, W. F., Abedon, B. G. \& Ordás, A. (2005a). Effects of selection for the timing of vegetative phase transition on corn borer (Lepidoptera: Noctuidae and Crambidae) damage. Journal of Economic Entomology 98 , 982-987.

Revilla, P., Tracy, W. F., Soengas, P., Ordás, B., Ordás, A. \& Malvar, R. A. (2005b). Vegetative phase transition and corn borer resistance of shrunken2 versus sugaryl sweet corn near-isogenic inbred lines. Journal of the American Society for Horticultural Science 130, 64-67.

Riedeman, E. S., Chandler, M. A. \& Tracy, W. F. (2008). Divergent recurrent selection for vegetative phase change and effects on agronomic traits and corn borer resistance. Crop Science 48, 1723-1731.

SAS (2000). The SAS System. SAS OnlineDoc.HTML Format. Version 8. Cary, NC, USA: SAS Institute. Available online at: http://support.sas.com/documentation/ onlinedoc/v82/index.html (verified 6 April 2009).

Schaffer, H., Yardley, D. \& Anderson, W. W. (1977). Drift or selection: a statistical test of gene frequency variation over generations. Genetics 87, 371-379.

Tojo Soler, C. M., Sentelhas, P. C. \& Hoogenboom, G. (2005). Thermal time for phenological development of four maize hybrids grown off-season in a subtropical environment. The Journal of Agricultural Science, Cambridge 143, 169-182.

TollenaAr, M. \& Lee, E. A. (2002). Yield potential, yield stability and stress tolerance in maize. Field Crops Research 75, 161-169.

Williams, W. P., David, F. M., Buckley, P. M., Hedin, P. A., Baker, G. T. \& Luthe, D. S. (1998). Factors associated with resistance to fall armyworm (Lepidoptera: Noctuidae) and southwestern corn borer (Lepdidoptera: Crambidae) in corn at different vegetative stages. Journal of Economic Entomology 91, 1471-1480. 